\title{
Six-month leuprorelin acetate depot formulations in advanced prostate cancer: a clinical evaluation
}

This article was published in the following Dove Press journal:

Clinical Interventions in Aging

24 April 2013

Number of times this article has been viewed

\author{
UIf W Tunn' \\ Damian Gruca ${ }^{2}$ \\ Peter Bacher ${ }^{3}$ \\ 'Urological Department, Prostate \\ Center, Offenbach, Germany; ${ }^{2} \mathrm{AbbVie}$ \\ Deutschland $\mathrm{GmbH}$ and Co, KG, \\ Ludwigshafen, Germany; ${ }^{3} \mathrm{AbbVie}$, \\ North Chicago, IL, USA
}

\begin{abstract}
For nearly three decades, gonadotropin-releasing hormone (GnRH) agonists, particularly leuprorelin acetate (LA), have served as an important part of the treatment armamentarium for prostate cancer. The introduction of LA depot formulations provided a significant improvement in the acceptance of this therapy; however, their indicated treatment duration of 1 to 4 months was still not long enough to satisfy all medical needs. For this reason some manufacturers developed new injectable formulations that provide testosterone suppression for 6 months. This review article assesses key publications in order to compare these longacting, commercially available, LA depot formulations and their clinical performance. The literature search identified 14 publications; by excluding reviews, duplications, and non-English articles, only three original papers describing clinical trial remained for review: two focused on microsphere-based LA formulations with either a $30 \mathrm{mg}$ or $45 \mathrm{mg}$ dose and one focused on a gel-based leuprorelin acetate with a $45 \mathrm{mg}$ dose. All products were tested in individual clinical trials and have demonstrated their efficacy and safety.
\end{abstract}

Keywords: androgen deprivation therapy, GnRH agonist, leuprorelin acetate, prostate cancer, leuprolide acetate

Gonadotropin-releasing hormone $(\mathrm{GnRH})$ agonists, including leuprorelin acetate (LA), have served as an important part of the treatment armamentarium for hormonesensitive prostate cancer for nearly three decades. Initially this form of androgen deprivation therapy (ADT) was cumbersome, painful for patients, and challenging for physicians as they involved daily injections at the practitioner's office, severely curtailing patients' quality of life and increasing adverse effects, such as injection site pain and reaction. ${ }^{1}$

However, the introduction of long-acting LA depot formulations has provided a significant improvement in the acceptance of this therapy, although the initial 1 to 4 month therapies did not have a sufficient duration to satisfy all medical needs. For this reason some manufacturers developed new injectable formulations that provide testosterone suppression for 6 months. These formulations were individually tested in clinical trials to evaluate their benefit-risk profiles as the basis of regulatory approvals.

\section{Therapeutic background}

Prostate cancer $(\mathrm{PCa})$ is a solid tumor with a high responsiveness to systemic hormonal therapy. It was described as early as 1840 by Hunter, ${ }^{2}$ who noted that physiologic prostatic epithelium demonstrated signs of atrophy after physical castration. A century later in 1941, Huggins ${ }^{3,4}$ showed that a level of testosterone and prostate-specific 
antigen (PSA) must be maintained in order for prostate cancer cells to grow and that a suppression of these levels induces a reduction in tumor size. Thus, the treatment of PCa was originally surgical castration or the use of estrogen therapy, and ADT in this form was introduced into the strategy of prostate cancer treatment. ${ }^{5}$ In 1971, research performed by Schally et al led to the presentation of a new form of ADT luteinizing hormone-releasing hormone (LHRH) or GnRH agonists. ${ }^{6} \mathrm{GnRH}$ agonists were less cardiotoxic than estrogens and offered an easy, more patient-friendly, and reversible method of ADT that proved to be oncologically equivalent to surgical castration. ${ }^{7}$

Initially, the use of GnRH agonists took the form of daily intramuscular or subcutaneous injections. ${ }^{8}$ This required daily visits to the oncologist or urologist and greatly increased the chance of adverse effects, such as injection site reactions and injection site pain, but also made patient compliance with therapy more difficult. ${ }^{9}$ Over the last 20 years, extended release formulations of $1,3,4$, and 6 months have been developed, significantly increasing patient acceptance to therapy and easing treatment burdens for physicians.

Since their introduction, the GnRH agonists have been used either as monotherapy or in combination with antiandrogens, especially for the prevention of flare-ups shortly after the start of treatment. Table 1 contains European Urology Association guidelines for the use of ADT in various PCa disease situations. ${ }^{10}$

\section{Mechanism of action}

Although the mechanism of action of LA is well understood, ${ }^{11}$ certain aspects of its pharmacology should be noted. The competitive occupation of LH receptors by LA in the anterior pituitary gland leads to their reactive downregulation, which results in the cessation of sex steroid production in the gonads after an initial flare effect. This can be considered an all-or-nothing principal, which does not allow for dosedependent testosterone (or estrogen) response. The result is the achievement of castration-equivalent sex steroid levels. The reason testosterone levels in men do not reach zero lies in the adrenal pathway of cholesterol metabolism, which is not affected by the action of LA on the hypothalamicpituitary-gonadal axis or bilateral orchiectomy. ${ }^{12}$

Despite the maintenance of castration levels of androgens in serum, prostate cancer usually progresses and can eventually reach the castration resistant (CRPC) stage. It has been demonstrated that the production of androgens also takes place in prostatic tumor cells, promoting tumor progression. ${ }^{13,14}$ In order to counteract this mechanism for fueling the growth of CRPC cells, new agents have been discovered, such as abiraterone acetate, enzalutamide (formerly known as MDV3100), and orteronel (TAK-700). These new agents target either the androgen receptor within the tumor cell directly, or counteract the androgen production through enzyme inhibition. ${ }^{15}$ In the vast majority of patients, the use of GnRH agonists continued as the base therapy while many of these new compounds were tested. Due to the fact that the development of the new 6-month LA formulations and the new CRPC drugs were conducted at approximately the same time, little is known about their concomitant use.

\section{Formulations}

Although the active pharmacological ingredient (API) is the same for all leuprorelin acetate products, there are significant differences in the way their formulation is designed and how these differences affect their individual pharmacological profile.

Over the last few years several different manufacturers have developed a variety of GnRH agonist formulations that have been approved for a 6-month treatment interval based on their ability to suppress testosterone below the castration level of $50 \mathrm{ng} / \mathrm{dL}$ in patients with prostate cancer. These products include two formulations of the microsphere-based LA (Lupron ${ }^{\circledR}$, Lucrin $^{\circledR}$, Daronda ${ }^{\circledR}$, Sixantone $^{\circledR}$, Procren ${ }^{\circledR}$, Procrin $^{\circledR}$ [name varies by country]) with either $30 \mathrm{mg}$ or $45 \mathrm{mg}$ doses.

The $30 \mathrm{mg}$ dose is mainly used in Europe, Asia, and Latin America, whereas the $45 \mathrm{mg}$ doses were introduced either as microspheres $\left(\right.$ Lupron $\left.^{\circledR}\right)$ in the USA only or as a gel-based formulation $\left(\right.$ Eligard $^{\circledR}$ ) in the EU and the USA.

Based on the different delivery technologies, regardless of API, some differences in clinical performance exist between the formulations that need to be discussed. While all iterations of LA have an identical molecular structure, the delivery system of each varies considerably. For many years LA has been delivered by only using a lyophilized, microsphere, drug depot delivery system.

The microsphere-based LA products achieve their drug release in a biphasic manner. In the first phase the product is released within a relatively short time from the surface of the spheres, and this functions as the initiation dose and establishes an effective plasma concentration. ${ }^{16}$ In the second phase, the microspheres are "digested" over 6 months and release the API as a maintenance dose to achieve the same constant plasma concentrations over time. The chemical compositions of the microspheres differ slightly between 
Table I Indications for hormonal therapy

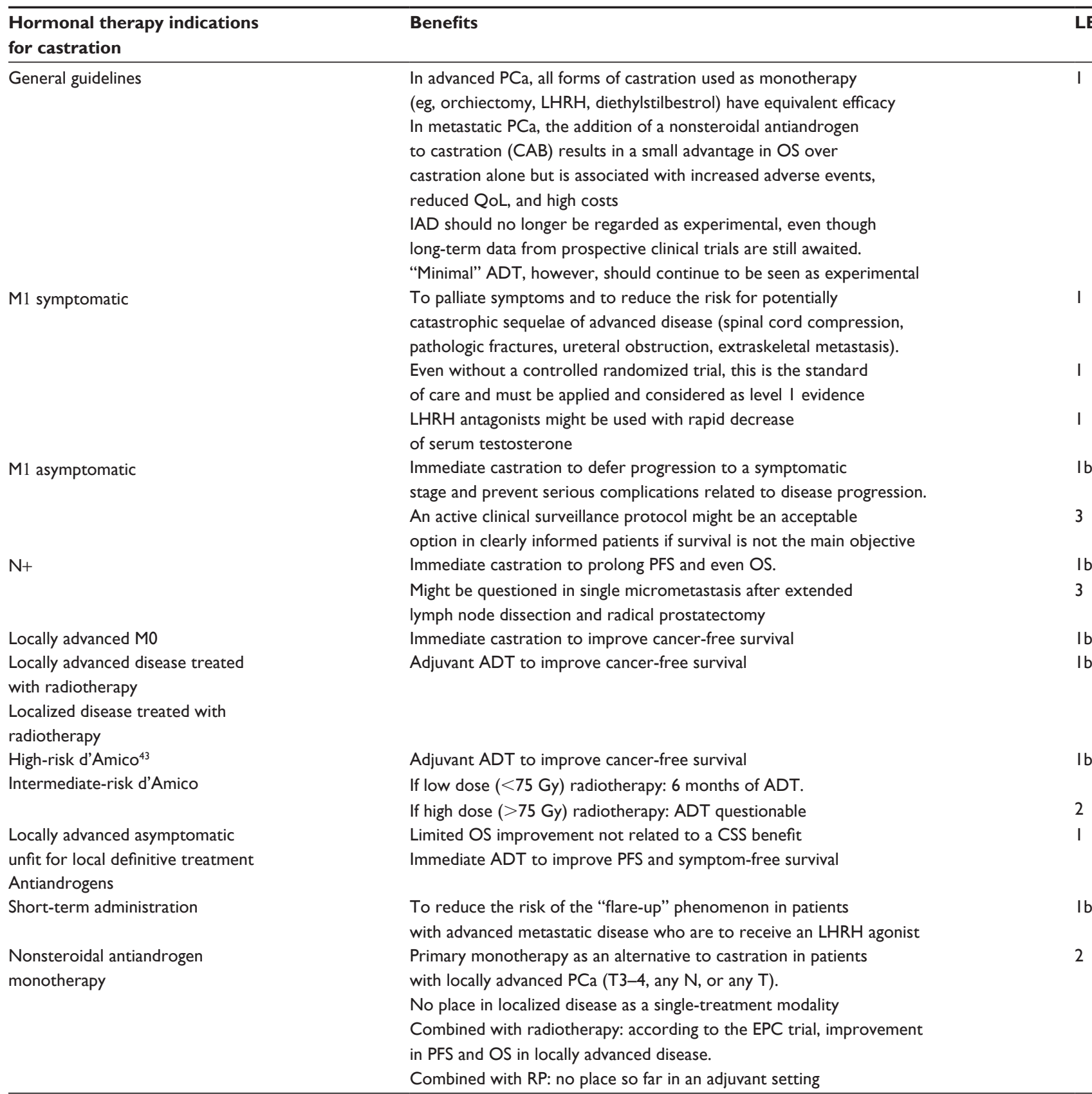

Note: Reprinted from European Urology, Vol 59/edition 4, Mottet N, Bellmunt J, Bolla M,et al, EAU Guidelines on Prostate Cancer. Part II: Treatment of Advanced, Relapsing, and Castration-Resistant Prostate Cancer, 572-583, Copyright (201 I), with permission from Elsevier. ${ }^{10}$

Abbreviations: IAD, intermittent androgen deprivation; ADT, androgen-deprivation therapy; CAB, complete androgen blockade; CSS, cancer-specific survival; EPC, Early Prostate Cancer Trialists' Group; LE, level of evidence; LHRH, luteinizing hormone-releasing hormone; QoL, quality of life; OS, overall survival; PCa, prostate cancer; PFS, progression-free survival; RP, radical prostatectomy; M1, metastatic patient; M0, no metastases; N, nodes; T, tumor; Gy, gray.

the 1-, 3-, 4-, and 6-month formulations and determine the timeframe over which API is released.

Eligard, on the other hand, is a gel-based formulation delivered by using a biodegradable polymer of D,L-lactideco-glycolide dissolved in N-methyl-2-pyrolidone. ${ }^{8}$ In this delivery system, the polymer is provided separately from the lyophilized drug compound (LA) and must be mixed within 30 minutes or less of injection. ${ }^{17}$ It is injected in a liquid form that condenses into a solid subcutaneous depot, which releases the drug over time. ${ }^{18}$ This transformation is independent of body temperature and can occur in vivo as well as ex vivo. Over the treatment period of 6 months, the gel is slowly dissolved and the API is released into the blood.

The microsphere-based LA was compared directly to the gel-based LA in only one phase I study. This singlecenter trial was conducted with 1-month depots $(7.5 \mathrm{mg})$

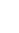

(

.

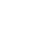


in 32 healthy male volunteers (mean age $38.3 \pm 8.4$ years; range 21-52 years). The pharmacokinetic measurements showed an initially higher release of LA from microspheres compared to gel-based product $\left(\mathrm{C}_{\max } 27.0 \pm 4.9 \mathrm{ng} / \mathrm{mL}\right.$ versus $19.0 \pm 8.0 \mathrm{ng} / \mathrm{mL}$ at $\mathrm{T}_{\max } 1.0 \pm 0.4$ hours versus $2.1 \pm 0.8$ hours). After an initial lower release of LA from the gel-based LA formulation, the total area under the curve was greater from the gel-based formulation than for microspheres $(479 \pm 132.6 \mathrm{ng} \cdot$ hours $/ \mathrm{mL}$ versus $248 \pm 65.0 \mathrm{ng} \cdot \mathrm{hours} / \mathrm{mL})$, which resulted in longer testosterone suppression (49 days versus 35 days). ${ }^{19}$

Based on the promising data from early development, pivotal trials were conducted to achieve registrations for the 6-month formulations. This review article identifies key publications of now commercially available 6-month depot formulations of LA and evaluates their clinical performance.

\section{Materials and methods}

A literature search was conducted in multiple biomedical/ pharmaceutical databases beginning in June 2012. The initial search was not limited by language or publication date, and the following databases and resources were searched: Medline (1950-2012), Embase (1974-2012), SciSearch (1990-2012), Biosis Previews (1926-2012), International Pharmaceutical Abstracts (1970-2012), Derwent Drug File (1983-2012), and Pascal (1973-2012).

The major subjects for the search were leuprorelin acetate 6-month depots and prostate cancer, combined with the following keywords and phrases: mechanism of action, efficacy, safety, pharmacokinetics (PK), pharmacodynamics (PD), along with patient perspective on quality of life, product preferences, satisfaction, convenience, cost, benefit, and health economics. We excluded from the review non-English articles, reviews and duplications, nonoriginal papers and case reports.

\section{Results}

The literature search identified twelve publications for three different products: two microsphere-based leuprorelin acetate formulations of either $30 \mathrm{mg}$ or $45 \mathrm{mg}$ dose depots and a gelbased leuprorelin acetate $45 \mathrm{mg}$ dose depot formulation. ${ }^{1,20-30}$ Of the twelve publications identified, only three original papers of the 6-month formulations fulfilled the criteria for comparison in this review (Table 2).

\section{Efficacy and safety}

The safety and efficacy of leuprorelin acetate depots have been studied at each formulation level and published by Kienle and Lubben (1-month depot), ${ }^{31}$ Tunn et al (1- and 3 -month depots), ${ }^{32}$ Jocham (3-month depot), ${ }^{33}$ Tunn and Wiedey (3- and 6-month depots), ${ }^{1}$ and Spitz et al (6-month depot $)^{20}$ for microsphere-based LA formulations. Gel-based LA was tested separately and published by Perez-Marreno et al (1-month depot), ${ }^{34}$ Chu et al (3-month depot), ${ }^{35}$ and Crawford et al (6-month depot). ${ }^{28}$

\section{Microsphere-based $30 \mathrm{mg}$ LA depot}

In a study by Tunn and Wiedey ${ }^{1}$ comparing the LA 3-month (11.25 mg) depot to the LA 6-month (30 mg) depot formulations, efficacy parameters again included the reduction of serum testosterone to castrate levels and the reduction of PSA levels. Tunn and Wiedey ${ }^{1}$ found that in 178 patients, results were similar between the two groups. Median values of testosterone and rate of response showed no relevant differences. PSA levels decreased $88 \%$ and $89 \%$ in 3-month and 6-month groups, respectively. In the 3-month treatment group, $77.6 \%$ of patients experienced an adverse event (AE) while $79.2 \%$ of patients in the 6 -month group experienced an AE. Other safety variables were similar, with $3.4 \%$ and $4.2 \%$ of patients experiencing an AE leading to withdrawal, $12.1 \%$ and $15.8 \%$ of patients experiencing a serious adverse event (SAE), and two and four deaths occurring in the study in the 3-month and 6-month groups, respectively. Most common AEs included flushing (43.1\%,34.2\%, respectively), increased sweating $(10.3 \%, 5.8 \%)$, injection site induration $(3.4 \%, 5.8 \%)$, and fatigue $(1.7 \%, 1.7 \%)$.

Table 2 Summary of included publications

\begin{tabular}{|c|c|c|c|}
\hline Formulation & Microsphere-based 30 mg & Microsphere-based 45 mg & Gel-based 45 mg \\
\hline \multirow[t]{4}{*}{ Title } & Safety and clinical efficacy & Efficacy and Safety of leuprolide & A I2-month clinical study of LA-2585 \\
\hline & of a new 6-month depot formulation & acetate 6-month depot for suppression & $(45.0 \mathrm{mg})$ : a new 6-month subcutaneous \\
\hline & of leuprorelin acetate in patients & of testosterone in patients & delivery system for leuprolide acetate \\
\hline & with prostate cancer in Europe & with prostate cancer & for the treatment of prostate cancer \\
\hline \multirow[t]{3}{*}{ Author } & UW Tunn and K Wiedey' & A Spitz, JM Young, L Larsen, & E David Crawford, Oliver Sartor, \\
\hline & & C Mattia-Goldberg, J Donnelly, & Franklin Chu, Ramon Perez, Gary \\
\hline & & and $\mathrm{K}$ Chwalisz ${ }^{20}$ & Karlin, and J Steve Garrett ${ }^{28}$ \\
\hline Journal & Prostate Cancer and Prostatic Diseases & Prostate Cancer and Prostatic Diseases & Journal of Urology \\
\hline
\end{tabular}




\section{Microsphere-based $45 \mathrm{mg}$ LA depot}

Spitz et $\mathrm{al}^{20}$ also studied safety and efficacy in a microspherebased LA $45.0 \mathrm{mg}$ 6-month formulation over 12 months. The primary endpoint for this study was the proportion of patients with suppressed serum testosterone, which was achieved in 93.4\% of 151 subjects within the first 4 weeks of the study and maintained for 24 weeks with each depot injection. In addition, after week 14 of the study, PSA levels were reduced to below $3 \mathrm{ng} / \mathrm{mL}$ and remained there through the end of the study. Hot flush was reported by $58.3 \%$ of subjects, injection site pain was reported by $17.9 \%$, and fatigue was reported by $11.9 \%$.

\section{Gel-based 45 mg LA depot}

The safety and efficacy of the gel-based LA $45.0 \mathrm{mg}$ 6-month depot formulation was studied by Crawford et $\mathrm{al}^{28}$ in a 12-month open-label study of 111 subjects. The primary endpoint was the reduction of serum testosterone to castrate level and the reduction of PSA. Of the 111 subjects, 93\% completed the study. Testosterone suppression was achieved by $99 \%$ of subjects within 28 days (mean 21.2 days). In addition, PSA was reduced from $39.8 \pm 21.5 \mathrm{ng} / \mathrm{mL}$ to $1.2 \pm 0.3 \mathrm{ng} / \mathrm{mL}$ after 12 months. Eighty-two subjects reported 211 AEs, only one of which was considered to be severe and not related to the study drug. The most common AEs included hot flush, injection site burning, fatigue, testicular atrophy, and gynecomastia.

In these studies of 6-month (30 mg and $45 \mathrm{mg}$ ) formulations, the results of safety and efficacy endpoints were remarkably similar. Incidence of adverse events was also comparable across these studies. Results of the pivotal studies are summarized in Table 3. These studies used similar efficacy and safety endpoints and parameters, allowing a direct comparison.

\section{Discussion}

Based on the above described data, the overall efficacy and safety of all three formulations appeared to be similar. However, the amount of data is still limited so it is more important to compare clinical performance with the established 1-, 3-, and 4-month formulations.

\section{Low-dose microsphere depot}

The low-dose microsphere formulations have been studied at a variety of levels. Kienle and Lubben ${ }^{31}$ assessed the

Table 3 Summary of pivotal study results

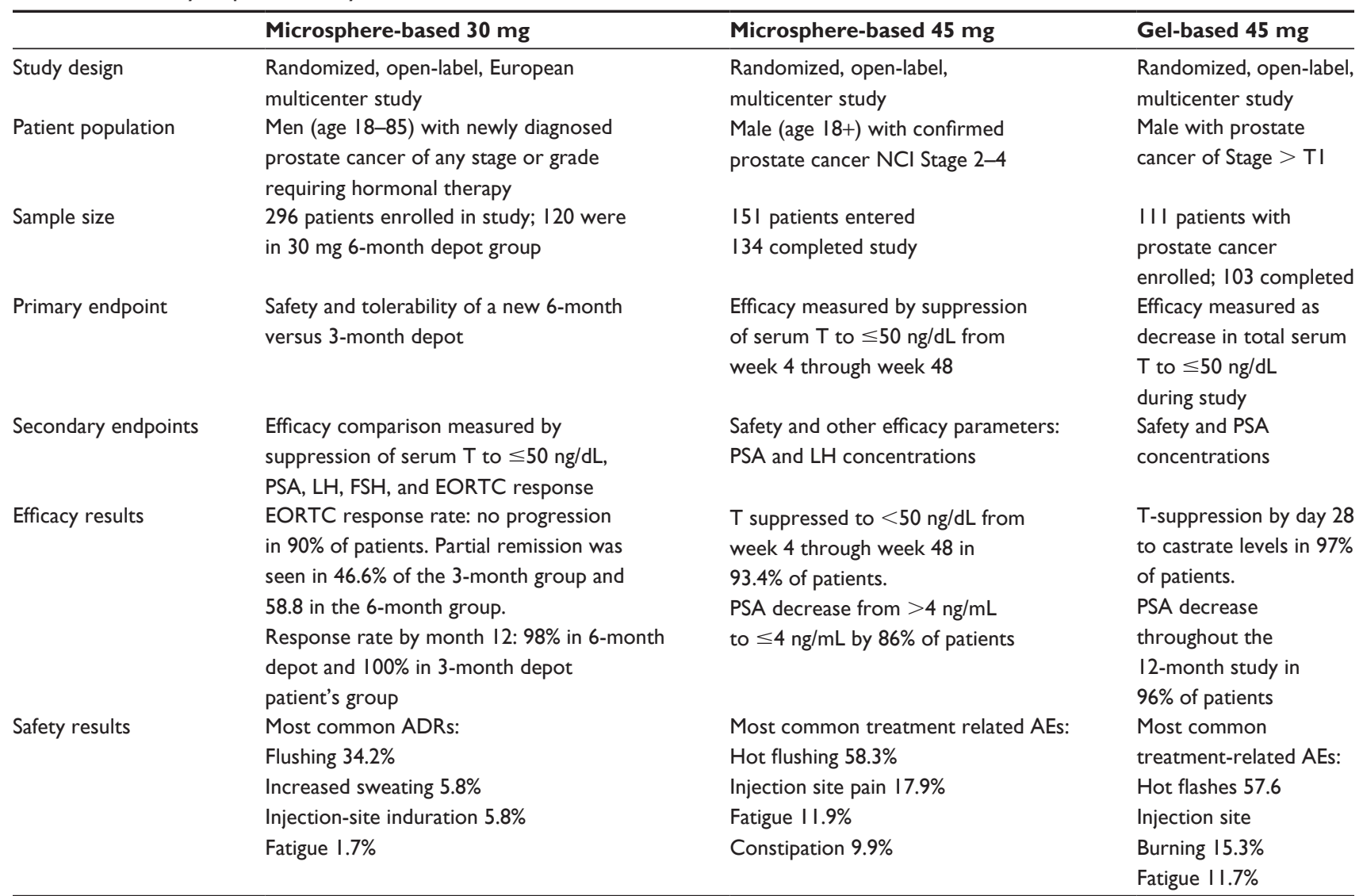

Abbreviations: $\mathrm{NCl}$, National Cancer Institute; TI, tumor I; T, testosterone; PSA, prostate-specific antigen; LH, luteinizing hormone; FSH, follicle-stimulating hormone; EORTC, European Organization for Research and Treatment of Cancer; ADRs, adverse drug reactions. 
long-term use of an LA $3.75 \mathrm{mg}$ monthly depot formulation in patients with $\mathrm{PCa}$ for more than 3 years, with the aim of determining if LA could reduce and maintain testosterone to castration levels over a 45-month period. In this study, each monthly injection of LA was followed by an initial burst of LA in the blood, reaching a steady state within 2 days of injection. Testosterone levels were reduced as were dihydrotestosterone, $\mathrm{LH}$, and follicle-stimulating hormone. Adverse events included fatigue (15\%), headaches (5\%), and local pain at injection site $(4.4 \%)$.

Tunn et $\mathrm{al}^{32}$ compared the LA $3.75 \mathrm{mg} 1$-month and the $11.25 \mathrm{mg} 3$-month depot formulations. In this study 15 patients received the $3.75 \mathrm{mg} 1$-month depot and a further 27 patients received the $11.25 \mathrm{mg} 3$-month depot. Both groups showed a reduction of testosterone and dihydrotestosterone to castration levels within 1 month, which was maintained over the 9-month study period. PSA was decreased to $97.8 \%$ in the 1-month depot group and $96.6 \%$ in the 3-month depot group. Both groups also showed similar disease progression at $6.7 \%$ for the 1-month group and 3\% in the 3-month group. Adverse events were also similar for both groups with the most common being hot flush and sweating.

Thus, the LA low-dose formulations of 1 month $(3.75 \mathrm{mg})$ and 3 months $(11.25 \mathrm{mg})$ show characteristics that were repeated in the $30 \mathrm{mg}$ 6-month depot formulation. Tunn and Wiedey ${ }^{1}$ found that the LA 6-month depot formulation (30 $\mathrm{mg}$ ) reduced serum testosterone to castrate levels during the first month of treatment and that these levels were maintained in the same manner as in the 1- and 3-month depot formulations. The response rate in terms of $\mathrm{T}$ suppression below castration level at 12 months was $98 \%$ for 6-month and $100 \%$ for 3 -month formulations. The 6 -month formulation was also comparable to earlier depots in the reduction of PSA, showing an $89 \%$ reduction compared to an $88 \%$ reduction in the 3-month $11.25 \mathrm{mg}$ depot. Adverse events were also similar; the most common AEs were flushing, sweating, and injection site induration.

\section{High-dose microsphere depot}

High-dose LA microsphere formulations, including the $7.5 \mathrm{mg}$ 1-month depot, the $22.5 \mathrm{mg} 3$-month depot, and the $45 \mathrm{mg}$ 6-month depot formulations, have been studied by Sharifi et $\mathrm{al}^{36-38}$ and Spitz et al. ${ }^{20}$

In a recent study, Spitz et $\mathrm{al}^{20}$ found that $93.4 \%$ of patients achieved the primary endpoint of suppression of testosterone to castrate levels by the fourth week of the study, maintaining that level through 48 weeks. Flushing and injection site reactions were the most commonly reported AEs.

\section{Gel-based high dose depot}

LA is also available in 1-, 3-, and 6-month depots in the gelbased formulation. These formulations have been studied by Perez-Marreno et al, ${ }^{34} \mathrm{Chu}$ et al, ${ }^{35}$ and Crawford et al. ${ }^{28}$

In a 6-month study of the LA 1-month high-dose $(7.5 \mathrm{mg})$ depot formulation, Perez-Marreno et $\mathrm{al}^{34}$ found that the mean (standard deviation) serum testosterone level was 6.12 (4.3) ng/dL among the 120 patients and that no patient experienced a breakthrough during treatment. Again, the most common AEs were hot flashes, fatigue, dizziness, and injection site burning sensation.

Similarly, Chu et $\mathrm{al}^{35}$ studied 117 patients who received a $22.5 \mathrm{mg} 3$-month depot formulation for 6 months. Serum testosterone was decreased to castrate levels in $98 \%$ of patients by day 28 and was maintained throughout the study. PSA was also decreased by $98 \%$. The most commonly reported AEs were hot flashes, fatigue, nausea, and dizziness.

A 6-month, gel-based, LA formulation (45 mg) was studied by Crawford et al. ${ }^{28}$ In this study, 111 patients received a $45 \mathrm{mg}$ 6-month depot dose of LA over the course of 12 months (two injections). Of these patients, 103 completed the study; 109 patients achieved testosterone suppression by day 28 , and PSA declined by $97 \%$ from baseline. Mild to moderate hot flashes were the most commonly reported AE.

\section{Microsphere (30 and $45 \mathrm{mg}$ ) and gel-based (45 mg) formulations}

In the three 6-month LA depot formulations studied, ${ }^{1,20,28}$ primary endpoints of serum testosterone suppression to castrate levels, observed decreases of PSA, and incidence of adverse events were similar across the board. Efficacy endpoints for the microsphere-based LA $30 \mathrm{mg}$ depot formulation showed a response rate of $98 \%$, no progression in $90 \%$ of patients, remission rate of $58.5 \%$, and $89 \%$ decrease in observed PSA levels. In the microsphere-based LA $45 \mathrm{mg}$ 6-month depot formulation, serum testosterone was suppressed to $<50 \mathrm{ng} / \mathrm{dL}$ from week 4 through week 48 in $93.4 \%$ (95\% confidence interval [CI] $89.2 \%, 97.6 \%$ ) of patients. For the prespecified endpoint, serum T was suppressed to $<50 \mathrm{ng} / \mathrm{dL}$ from week 4 to 48 in $93.6 \%$ of subjects ( $90 \%$ CI $90.2 \%$, $97.0 \%$ ). The gel-based LA $45 \mathrm{mg}$ depot formulation showed that a $97 \%$ reduction of serum testosterone levels was reached within 28 days and maintained until the study end. PSA levels also declined throughout the study for $96 \%$ of patients. In all of these studies, the most common AEs were hot flush, injection site reactions, and fatigue.

In studies of patient preferences, the advent of LA formulations ranging from 30 to $45 \mathrm{mg}$ dose depots has 
greatly improved the quality of life for many prostate cancer patients. ${ }^{39}$ The increased time between injections and office visits has a variety of repercussions. Fewer total injections mean reduced pain and stress for patients and should also be associated with fewer injection-site reactions. It can be hypothesized that key efficacy and safety aspects go handin-hand with an improvement of compliance and adherence for the 6-month formulations. In conjunction with a lower frequency of clinic visits due to a reduced need for injections or the treatment of injection-related side effects, it can be assumed that there is a pharmacoeconomic benefit for the 6-month depot even when overall product costs are the same on an annual basis. ${ }^{40,41}$ These aspects could remain strong regardless whether the formulations are used continuously or intermittently. ${ }^{42}$ Due to the fact that drug prices differ from country to country, specific cost assessments are needed to support this pharmacoeconomic argument more broadly.

\section{Conclusion}

All three 6-month LA formulations fulfilled the efficacy and safety criteria for the registration in countries of submission based on their pivotal trial data. These products are an additional tool in the treatment of prostate cancer. Due to their longer treatment duration, an improvement of compliance and adherence for the 6-month formulations could be considered. In conjunction with a lower frequency of clinic visits due to a reduced need for injections or the treatment of injection-related side effects, it can be assumed that there is a pharmacoeconomic benefit for the 6-month depot even when overall product costs are the same on an annual basis. Based on these arguments, it can be postulated that the 6-month depots could become preferred formulations for both physicians and for patients with stable disease.

\section{Acknowledgments}

The authors thank Elaine Hanna of AbbVie for medical writing and editorial assistance and Kristina Kligys of AbbVie for editorial assistance.

\section{Disclosure}

Dr Tunn has no conflict of interest to declare. Drs Gruca and Bacher are employees of AbbVie and own Abbott and/or AbbVie stock. AbbVie is the producer of two products discussed in this article.

\section{References}

1. Tunn UW, Wiedey K. Safety and clinical efficacy of a new 6-month depot formulation of leuprorelin acetate in patients with prostate cancer in Europe. Prostate Cancer P D. 2009;12(1):83-87.
2. Androustos G. John Hunter (1728-1793): fondateur de la chirugie scientifique etpercurseur de l'urologic. Prog Urol. 1998;8:1087-1096.

3. Huggins C, Hodges CV. Studies on prostatic cancer: I. The effect of castration, of estrogen and of androgen injection on serum phosphatases in metastatic carcinoma of the prostate. Cancer Res. 1941;1:293-297.

4. Huggins C, Stevens RE, Hodges CV. Studies on prostatic cancer. II. The effect of castration on advanced carcinoma of the prostate gland. Arch Surg-Chicago. 1941;43:209-228.

5. Wein LRK, Alan J, Novick Andrew C, Partin Alan W, Peters Craig A, editors. Campbell-Walsh Urology, 9th ed. [Philadelphia, PA]:Elsevier; 2007.

6. Schally AV, Kastin AJ, Arimura A. Hypothalamic follicle-stimulating hormone (FSH) and luteinizing hormone (LH)-regulating hormone: structure, physiology, and clinical studies. Fertil Steril. 1971;22(11):703-721.

7. Seidenfeld J, Samson DJ, Hasselblad V, et al. Single-therapy androgen suppression in men with advanced prostate cancer: a systematic review and meta-analysis. Ann Intern Med. 2000;132(7):566-577.

8. Cox MC, Scripture CD, Figg WD. Leuprolide acetate given by a subcutaneous extended-release injection: less of a pain? Expert Rev Anticancer Ther. 2005;5(4):605-611.

9. Crawford ED, Phillips JM. Six-month gonadotropin releasing hormone $(\mathrm{GnRH})$ agonist depots provide efficacy, safety, convenience, and comfort. Cancer Manag Res. 2011;3:201-209.

10. Mottet N, Bellmunt J, Bolla M, et al. EAU guidelines on prostate cancer. Part II: Treatment of advanced, relapsing, and castration-resistant prostate cancer. Eur Urol. 2011;59(4):572-583.

11. Persad R. Leuprorelin acetate in prostate cancer: a European update. Int J Clin Pract. 2002;56(5):389-396.

12. Labrie F. Medical castration with LHRH agonists: 25 years later with major benefits achieved on survival in prostate cancer. $J$ Androl. 2004;25(3):305-313.

13. Locke JA, Guns ES, Lubik AA, et al. Androgen levels increase by intratumoral de novo steroidogenesis during progression of castrationresistant prostate cancer. Cancer Res. 2008;68(15):6407-6415.

14. Shore N, Mason M, de Reijke TM. New developments in castrateresistant prostate cancer. BJU Int. 2012;109 (Suppl 6):22-32.

15. Cannata DH, Kirschenbaum A, Levine AC. Androgen deprivation therapy as primary treatment for prostate cancer. J Clin Endocrinol Metab. 2012;97(2):360-365.

16. Lee M, Browneller R, Wu Z, Jung A, Ratanawong C, Sharifi R. Therapeutic effects of leuprorelin microspheres in prostate cancer. $A d v$ Drug Deliv Rev. 1997;28(1):121-138.

17. Tombal B, Berges R. Eligard. Advantages for optimal testosterone control. Eur Urol Suppl. 2007;5(18):900-904.

18. Ravivarapu HB, Moyer KL, Dunn RL. Sustained activity and release of leuprolide acetate from an in situ forming polymeric implant. AAPS Pharm Sci Tech. 2000;1(1):E1.

19. Perez-Marrero R, Tyler RC. A subcutaneous delivery system for the extended release of leuprolide acetate for the treatment of prostate cancer. Expert Opin Pharmacother. 2004;5(2):447-457.

20. Spitz A, Young JM, Larsen L, Mattia-Goldberg C, Donnelly J, Chwalisz K. Efficacy and safety of leuprolide acetate 6-month depot for suppression of testosterone in patients with prostate cancer. Prostate Cancer P D. 2012;15(1):93-99.

21. Crawford D, Phillips E. Six-month gonadotropin releasing hormone $(\mathrm{GnRH})$ agonist depots provide efiicacy, safety, convenience, and comfort. Cancer Manag Res. 2011;3(1):201-209.

22. Ouzaid I, Roupret M. The role of a 6-month depot form of hormone therapy in the treatment of advanced hormone-dependent prostate cancer: Results from the 'ELIRE' observational study. Prog Urol. 2011;21(12):866-874.

23. Tunn UW. A 6-month depot formulation of leuprolide acetate is safe and effective in daily clinical practice: a non-interventional prospective study in 1273 patients. BMC Urol. 2011;11:15.

24. Chavez B, Reilly T. Manic and psychotic symptoms following subcutaneous leuprolide in a male patient with no prior psychiatric history. J Clin Psy. 2010;71(12):1696-1698. 
25. Mostafa N, Chwalisz K, Larsen L, et al. Pharmacokinetics and Pharmacodynamics of Leuprolide Acetate 6-Month Depot in Patients With Prostate Cancer. J Clinv Pharmacol. 2010;50:1091.

26. Sethi R, Sanfilippo N. Six-month depot formulation of leuprorelin acetate in the treatment of prostate cancer. Clin Interv Aging. 2009;4:259-267.

27. Eligard Berges R. SUP (R) 6: achieving optimal testosterone control with the convenience of a twice -a-year formulation. Eur Urol Suppl. 2007;6(15):840-845.

28. Crawford ED, Sartor O, Chu F, Perez R, Karlin G, Garrett JS. A 12-month clinical study of LA-2585 (45.0 mg): a new 6-month subcutaneous delivery system for leuprolide acetate for the treatment of prostate cancer. J Urol. 2006;175(2):533-536.

29. Amo FH. Comparative analysis of six months formulation of LHRH analogues for prostate cancer treatment. Arch Esp Urol. 2010;63(4):275-281.

30. Young JM, Spitz A, Larsen L, Mattia-Goldberg C, Donnelly J, Chwalisz K. Efficacy and safety of a 6-month depot leuprolide acetate for the treatment of prostate cancer: results of a 48-week study. J Clin Oncol. 2010; Supplement:e15042.

31. Kienle E, Lubben G. Efficacy and safety of leuprorelin acetate depot for prostate cancer. The German Leuprorelin Study Group. Urol Int. 1996;56(Suppl 1):23-30.

32. Tunn UW, Bargelloni U, Cosciani S, Fiaccavento G, Guazzieri S, Pagano F. Comparison of LH-RH analogue 1-month depot and 3-month depot by their hormone levels and pharmacokinetic profile in patients with advanced prostate cancer. Urol Int. 1998;60 Suppl 1:9-16; discussion 16-17.

33. Jocham D. Leuprorelin three-month depot in the treatment of advanced and metastatic prostate cancer: long-term follow-up results. Urol Int. 1998;60(Suppl 2):18-24; discussion 35.

34. Perez-Marreno R, Chu FM, Gleason D, Loizides E, Wachs B, Tyler RC. A six-month, open-label study assessing a new formulation of leuprolide $7.5 \mathrm{mg}$ for suppression of testosterone in patients with prostate cancer. Clin Ther. 2002;24(11):1902-1914.
35. Chu FM, Jayson M, Dineen MK, Perez R, Harkaway R, Tyler RC. A clinical study of $22.5 \mathrm{mg}$. La-2550: a new subcutaneous depot delivery system for leuprolide acetate for the treatment of prostate cancer. J Urol. 2002;168(3):1199-1203.

36. Sharifi R, Soloway M. Clinical study of leuprolide depot formulation in the treatment of advanced prostate cancer. The Leuprolide Study Group. J Urol. 1990;143(1):68-71.

37. Sharifi R, Bruskewitz RC, Gittleman MC, Graham SD Jr, Hudson PB, Stein B. Leuprolide acetate $22.5 \mathrm{mg}$ 12-week depot formulation in the treatment of patients with advanced prostate cancer. Clin Ther. 1996;18(4):647-657.

38. Sharifi R, Browneller R. Serum testosterone suppression and potential for agonistic stimulation during chronic treatment with monthly and 3-month depot formulations of leuprolide acetate for advanced prostate cancer. J Urol. 2002;168(3):1001-1004.

39. Schulman C. Assessing the attitudes to prostate cancer treatment among European male patients. BJU Int. 2007;100(Suppl 1):6-11.

40. Odeyemi IA, Berges R, Bolodeoku J. Economic impact of different preparations of leuprolide acetate in the management of advanced prostate cancer. J Med Econ. 2007;10(2):135-146.

41. Tundia NL, Fuldeore M, Gruca D, Hass S, Bacher P, Bodhani A. Cost effectiveness of treatment with new 6-month leoprorelin acetate formulation in patients with advanced prostate cancer. Paper presented at: ISPOR 15th Annual European Congress 2012; Berlin, Germany.

42. Gruca D, Bacher P, Tunn U. Safety and tolerability of intermittent androgen deprivation therapy: a literature review. Int J Urol. 2012; 19(7):614-625.

43. D’Amico AV, Whittington R, Bruce Malkowicz S, et al. Biochemical outcome after radical prostatectomy, external beam radiation therapy, or interstitial radiation therapy for clinically localized prostate cancer. JAMA. 1998;290(11);969-974.
Clinical Interventions in Aging

\section{Publish your work in this journal}

Clinical Interventions in Aging is an international, peer-reviewed journal focusing on evidence-based reports on the value or lack thereof of treatments intended to prevent or delay the onset of maladaptive correlates of aging in human beings. This journal is indexed on PubMed Central, MedLine, the American Chemical Society's 'Chemical Abstracts

\section{Dovepress}

Service' (CAS), Scopus and the Elsevier Bibliographic databases. The manuscript management system is completely online and includes a very quick and fair peer-review system, which is all easy to use. Visit http://www.dovepress.com/testimonials.php to read real quotes from published authors. 